\title{
Inovasi Alat Distilasi Asap Cair dari Bahan Drum dan Pipa Stainless dengan Sirkulasi Pendingin Pompa Air Sebagai Penunjang Kegiatan Praktikum
}

\author{
Atak sumedi ${ }^{1}$, Alfrida ${ }^{2}$ \\ ${ }^{1}$ Laboratorium Hasil Hutan Non Kayu. Program Studi Teknologi Hasil Hutan Jurusan Teknologi \\ Pertanian. Politeknik Pertanian Negeri Samarinda \\ sumediatak@gmail.com \\ ${ }^{2}$ Laboratorium Rekayasa Kayu. Program Studi Teknologi Hasil Hutan. Jurusan Teknologi Pertanian. \\ Politeknik Pertanian Negeri Samarinda. \\ aalfrida38@gmail.com
}

\begin{abstract}
ABSTRAK
Peralatan distilasi di laboratorium sudah menjadi satu kebutuhan yang tidak bisa di pisahkan dengan dunia praktikum atau penelitian, perlu adanya inovasi bagi para Pranata Laboratorium Pendidikan (PLP) untuk mengembangan dan menunjang kegiatan praktikum dan penelitian di laboratorium. Oleh karena itu untuk mengatasi masalah yang di hadapi oleh para laboran atau peneliti berupa peralatan yang kurang memadahi sehingga berpengaruh terhadap kinerja laboratorium. Penelitian ini dilakukan untuk mengurangi keterbatasan peralatan yang ada di laboratorium sehingga kegiatan praktikum penelitian dan kegiatan pengabdian pada masyarakat dapat berjalan secara maksimal dan lancar. Proses pembuatan peralatan distilasi terdiri dari mesin las, gergaji listrik, gurinda sedangkan bahan yang digunakan tungku pengodokan kapasitas 5 liter yang berupa panci presto, yang pada tutupnya di buat lobang untuk dipasang pipa stainless berbentuk $L$ yang berfungsi untuk penyalur uap dari tunggku dengan diameter 2 inci dengan panjang $40 \mathrm{~cm}$, kemudian drum yang sudah disiapkan di buat lobang segi empat bagian tengahnya dengan ukuran $20 \times 15 \mathrm{~cm}$, selanjutnya buat lubang ditengah antara ujung kiri kanan drum dengan ukuran 2 inci,setelah itu potong pipa stainless sesuai kebutuhan yaitu dengan ukuran panjang $125 \mathrm{~cm}$, dengan diameter 2 inci dan masukkan pipa stainless tersebut kedalam lubang kanan kiri drum yang sudah di lubangi hingga tembus kemudian dilakukan pengelasan pada kedua ujungnya. selanjutnya buat lubang pada drum dan disambung dengan pipa stainless untuk saluran sirkulasi air pendingin pada drum sehingga air yang ada akan tetap dingin dan terjadi pendinginan yang sempurna dengan pompa air tersebut. Dari hasil pengujian peralatan distilasi menunjukkan pada 5 liter asap cair grade 3 setelah dilakukan distilasi menghasilkan rendemen asap cair grade 2 sebanyak 90,4\% atau 4,520 ml. Sedangkan asap cair grade 2 sebanyak 4,520 ml menghasilkan rendemen asap cair grade 1 sebanyak 90,7\% atau 4,100 ml. Untuk hasil asap cair grade 1 sangat baik dan warnanya bening dan sudah sesuai dengan standart SNI.
\end{abstract}

Kata kunci: Alat distilasi,inovasi,sederhana,praktikum,laboratorium.

\section{PENDAHULUAN}

Distilasi merupakan suatu proses pemisahan campuran secara fisika menjadi dua atau lebih produk dengan berdasar perbedaan titik didih (Kister, 1992). Pemisahan dengan metode distilasi senyawa dalam campuran yang memiliki titik didih lebih rendah akan mendidih kemudian uap tersebut melewati kondensator dan terkondensasi menjadi cairan kembali karena suhu dingin yang ada pada kondensor (Ledgrad, 2006).

Peralatan distilasi asap cair biasanya digunakan oleh masyarakat produsen asap cair, baik berupa limbah tempurung kelapa atau dari limbah-limbah yang lainnya. 
Dewasa ini penggunaan alat distilasi juga di gunakan di laboratorium namun dalam bentuk sederhana dan kapasitasnya sangat rendah.kegiatan praktikum di laboratorium dapat membuat proses belajar menjadi lebih bermakna (Abrahams dan Millar,2008).

Alat destilasi sederhana yang dikembangkan oleh beberapa ahli belum ada satupun yang disertai dengan pengukur suhu, sehingga kurang efektif dalam memisahkan campuran apabila suhu pemanasan yang dilakukan telah mencapai titik didih kedua senyawa yang bercampur. Hal ini yang menyebabkan kedua zat yang akan dipisahkan tersebut menguap,kemudian terkondensasi dan akirnya bercampur kembali.

\section{METODE PENELITIAN}

Waktu dan tempat penelitian.

Penelitian dilakukan selama 4 bulan mulai bulan September 2017 hingga Desember 2017, mulai dari persiapan bahan hingga penulisan.dan dilakukan di laboratorium Hasil Hutan Non Kayu Progran Studi Pengolahan Hasil Hutan Politeknik Pertanian Negeri Samarinda.

\section{Bahan dan alat penelitian}

Drum besar ukuran 90x80 cm, Pipa stainless diameter 2 inci 1 lonjor, Tungku penggodokan/ panci presto kapasitas 5 liter, las listrik dan las acetilin, Gergaji Listrik, Gurinda Listrik, Palu, Kawat las stainlis, Baut ukuran 12 mm, Kunci Pas 12 dan kunci ingris, Kompor gas lengkap, Gelas ukur, Jirigen dan botol penampungan asap cair. Pompa air, Selang 2 inci, Bor listrik

Persiapan bahan baku dengan menyiapkan drum besar ukuran 90x80 cm, kemudian di buat lobang persegi empat dengan ukuran $20 \times 15 \mathrm{~cm}$ dengan menggunakan mesin gurinda listrik dan setelah lobang sudah jadi bari dirapikan bekas belahan tadi sehingga tidak tajam yang dapat melukai tangan kita. Selanjutnya buat lobang pada ujung drum antara ujung dengan ujung dengan menggunakan bor listik dengan diameter 2 inci, lobang yang pertama di tengah-tengah diameter drum sedang labang ujung yang kedua pada pinggir bibir drum bagian bawah. Masukkan pipa stainless dengan panjang $125 \mathrm{~cm}$ hingga tembus ke lubang drum atas dengan lubang bawah sehingga terlihat menonjol keluar pipa stanlessnya dan kemudian dilakukan pengelasan pada kedua ujung pipa terhadap drum. Pengelasan awal menggunakan las acetilin agar tidak bocor dan diusahakan serapi mungkin baik ujung atas atau ujung bawah kemudian di gurinda sampai rapi bekas pengelasan tadi. Pada tungku penggodokan pada tutup atas kita lobangi dan dilakukan pengeboran untuk memasang pipa stanless yang sudah dipotong sepanjang $40 \mathrm{~cm}$ dan dibengkokkan berbentuk L dan pada ujungnya kita buatkan panel pengikat yang berfungsi untuk mengikat ke panci dan bisa dipasang baut.

\section{HASIL DAN PEMBAHASAN}

Dari hasil pengujian alat inovasi yang sudah dilakukan dengan bahan baku $100 \mathrm{Kg}$ pada setiap sampel uji di dapatkan asap cair yaitu pada sampel uji kayu macaranga di hasilkan sebanyak $5000 \mathrm{ml}$ grade 3 kemudian dilakukan destilasi ke grade 2 menghasilkan asap cair sebanyak $4.520 \mathrm{ml}$ asap cair, sedang grade 1 sebanyak $4.100 \mathrm{ml}$.

Untuk bahan tempurung kelapa di dapatkan asap cair sebanyak $5000 \mathrm{ml}$ grade 3 kemudian dilakukan destilasi ke grade 2 menghasilkan asap cair sebanyak $4.509 \mathrm{ml}$ asap cair, sedang grade 1 sebanyak $4.110 \mathrm{ml}$.

Untuk bahan pelepah sawit di dapatkan asap cair sebanyak $5000 \mathrm{ml}$ grade 3 kemudian dilakukan destilasi ke grade 2 menghasilkan asap cair sebanyak $4.595 \mathrm{ml}$ asap cair, sedang grade 1 sebanyak $4.103 \mathrm{ml}$. 


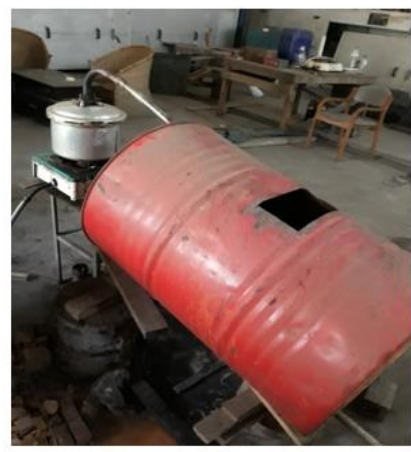

a

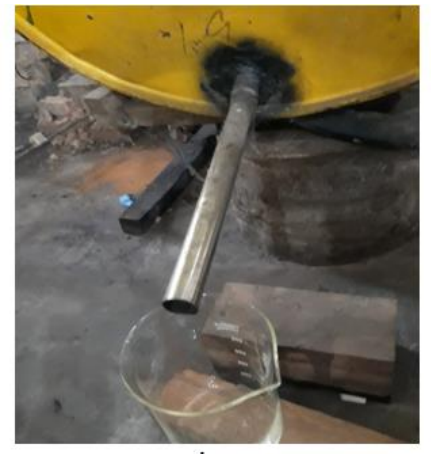

$b$

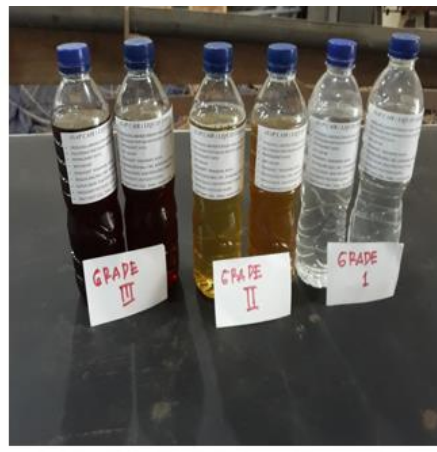

C

Gambar 1. a. Tungku distilasi b.Hasil distilasi c. Hasil uji grade

TabelI. Hasil uji coba alat distilasi sederhana

\begin{tabular}{ccccc}
\hline ULANGAN & JENIS BAHAN & GRADE 3 & GRADE 2 & GRADE 1 \\
\hline 1 & Macaranga & $5000 \mathrm{ml}$ & $4,520 \mathrm{ml}$ & $4,100 \mathrm{ml}$ \\
& Warna & Kuning kecoklatan & Kuning & Jernih \\
2 & Tempurung kelapa & $5000 \mathrm{ml}$ & $4,509 \mathrm{ml}$ & $4,110 \mathrm{ml}$ \\
& Warna & Kuning kecoklatan & kuning & Jernih \\
3 & Pelepah sawit & $5000 \mathrm{ml}$ & $4,495 \mathrm{ml}$ & $4,103 \mathrm{ml}$ \\
& Warna & Kuning kecoklatan & Kuning & Jernih \\
\hline
\end{tabular}

Sedangkan untuk warna asap cair memiliki kesamaan warna yaitu untuk grade 3 warna asap cair kuning kecoklatan dan asap cair grade 2 warna kuning sedang grade 1 warna asap cair jernih atau bening.

\section{KESIMPULAN}

Dari hasil pengujian alat denga $3 \mathrm{kali}$ ulangan dengan jenis bahan yang berbeda didapat hasil yangg rata-rata mendekati kesamaan hasil sehingga dapat dismpulakan bahwa pembuatan alat destilasi sederhana ini sudah mendekati baik dan dapat direkonendasikan untuk digunakan kegiatan praktikum dan penelitian mahasiswa atau pengabdian pada masyarakat. Dari hasil pewarnaan dan hasil destilasi sudah sesuai standar SNI.

\section{DAFTAR PUSTAKA}

Abrahams, L., \& Millar, R. 2008. Does Practical Work Really Work? A Study of the Effectveness of Practical Work as Teching and Learning Method in School Science Intenational Journal of Science Education.

Kister, H.Z. 1992. Distillation Design. New York. Mc graw-Hill, Inc.

Ledgrad, J. B. 2006. A Laboratary History of Chemical Walfar Agents. United sates: J.B. Ledgrad. 